\title{
Leadership Capability Assessment among Young Women before entering the Corporate World - A Study
}

\author{
${ }^{1}$ Dr. Sridevi Samineni \\ 1(Post Doctoral Research Fellow-UGC 2016-17, Department of Business Management, Osmania University, \\ Hyderabad. India,
}

\begin{abstract}
In the modern, fast moving business environment a new breed of leaders are required for the changing technological revolution and discovery needs. People at the top are expected to think fast and adapt to the changes by finding new ways to their teams. The ability to meet those challenges is based on a combination of confidence on self and confidence on people who lead. Great leaders always inspire with their specific personal characteristics which set them apart from others. It is a human nature to know how one reacts in an extreme or challenging situation and how one is able to think and act beyond the usual boundaries and make a real difference in the business world. This article will try to find answers whether the young women who are about to graduate and step into the corporate world are able to assess their leadership potential or else whether they are good leadership material for the organizations. As the research say that women bring uniqueness to the organizations.
\end{abstract}

Keywords: Capability, Capacity Enhancement, Self awareness, Self efficacy.

\section{Introduction}

Today organizations are set up to produce goods or provide services but major junk of the business is taken up by the services sector where people role have become crucial. In this way, there are consumers and clients that the organizations must satisfy within the external work environment where it operates. Even in the internal work environment, organization must satisfy its own workforce who are the key stake holders where leadership is effective, it must be employee friendly, consultative and participative, and the possibility of having excellent performance is high as against the poor performance that could come out of exploitative and authoritative leadership style. Good leadership in the contemporary business world should comprise of the ability of the leader to have clear vision and mission and being clear to foster innovativeness. A good leader should be able to perform well so as to make the subordinates are motivated and able to build their confidence and thereby enhance the follower's creativity to in turn and enhance organizational efficiency and better productivity and services. Why is capability building so important in a services context? In services, the work itself tends to be highly variable both in terms of content (such as the wide range of questions customers may have) and in form (such as the major swings in demand that may occur depending the time of day or year). Moreover, providing services usually means relying mainly on people, who are far more variable than machines. This compounded variability can make consistent delivery appear almost impossible, unless people are able to perceive the issues that are produced by variability, react to them, and provide solutions on a continuous basis. Over the long term, these capabilities become even more important so that the organization can identify new customer needs, take advantage of new opportunities, and create new value. Senior leaders and managers cannot know everything about what their customers want or how their products are doing. The closer people are to the front line, however, the more likely they are to have a real answer-but only if they have built skills in listening to customers and analyzing problems. Capability building thus involves more than just teaching people how to complete their day-to-day tasks. Instead, it focuses on a broader set of skills that increase each employee's value to the organization, such as learning to reach problems' root causes, or providing effective feedback. With the greater value that more skilled people can create, the organization will enhance its unique competitive position. That means tailoring the capability building to the organization's business context, culture, and needs especially to the factors that allow the organization to create value.

\section{Literature Review}

Employee effectiveness enhances organizational effectiveness which in turn implies the achievement of corporate objectives by means of collaborative efforts of the leaders and the team in a work group or units in the organization. Each unit throughout the organization along with the leaders making use of the best and appropriate situational styles must ensure the actualization of organizational goals then we can have organizational effectiveness. Young employees in the organization bring the new dynamism into the system. Akinboye (2004) says less than 5\% of managers in strategic sectors are women. Shapiro et al (2009) citing Gross and Scott (1990) state that generation 'X' workers that is, women born during 1961 to 1982 period were 
unwilling to put in the effort to get to the top of their careers. But that by year 2000, some women had become highly successful career women by using flexible work arrangements (FWAs) or in the alternative, leave the workplace temporarily for reproduction and raising of children. Leadership effectiveness refers to performance on the part of the leader that leads to the achievement of organizational goals of the group and a high level of group member's satisfaction (Cole, 2005). A leader must demonstrate good leadership by influencing the group members or subordinates to achieve the goals of the organization. The style of the leader can to a large extent determine the followership the leader gets, and how effective the organization could be. An employee centered leadership style will have the employees satisfied and motivate them to put in their best to achieve the goals of the organization.

\section{Objectives Of The Study}

1. To study and understand the self assessment capabilities of young women

2. To understand the dominant leadership capabilities that are possessed by the young women

3. To study how the young leaders are nurtured and trained in professional Colleges

\section{Methodology}

The study adopted a survey research design to investigate the leadership self assessment quality of young women when they are still in persuasion of education. This study is also aimed at understanding their capabilities at the learning stage and also their motivation level. 150 students from five purposefully selected colleges from the twin cities of Hyderabad and Secunderabad of Telangana State offering MBA programme only for women students. Thirty students from the college were randomly selected which counts the fifty percent of the students registered in the particular programme. Only students who are yet to enter the job market were taken up for the survey at the time of completion of the course work. The leadership Self- Assessment Questionnaire was a well conceived instrument developed by Udai Parekh. So the question of validating does not arise as it is a proven questionnaire.

\section{Self Assessment capability:}

\section{Analysis \& Interpretations}

Capable leadership and capable leaders are undoubtedly important factors in creating and maintaining the organizations success which can achieve outstanding and sustainable results. In today's complex and changing world, the need for strong leadership is greater than ever before. The following table-1 indicates the variables which are important in deciding the leadership capabilities of the young leader aspiring to enter into the corporate world.

Table:1

\begin{tabular}{|l|l|l|l|}
\hline Cross tabulation of Independent variables & Asymp. Sig. \\
\hline & Chi-Square & df & .000 \\
\hline Team work & 49.800 & 4 & .000 \\
\hline Clear communication & 25.733 & 4 & .014 \\
\hline interpersonal relationship & 12.533 & 4 & .000 \\
\hline good planning & 56.467 & 4 & .000 \\
\hline Good interpreter & 35.067 & 4 & .000 \\
\hline seeking advice & 78.800 & 4 & .000 \\
\hline enjoy analyzing & 60.867 & 4 & .000 \\
\hline problem solver & 26.467 & 4 & .003 \\
\hline comfortable in giving advises & 16.333 & 4 & .000 \\
\hline delegation work & 38.667 & 4 & .000 \\
\hline effective complaint handler & 40.467 & 4 & .000 \\
\hline good at directing & 53.133 & 4 & .000 \\
\hline Good at developing goals & 24.800 & 4 & .016 \\
\hline Good at implementing techniques & 12.133 & 4 & .000 \\
\hline appraising performance & 50.067 & 4 & .000 \\
\hline accept mistakes & 224.667 & 4 & .000 \\
\hline resolve conflicts & 43.733 & 4 & .000 \\
\hline believe in diversity & 30.867 & 4 & .000 \\
\hline thrive in change & 20.533 & 4 & .000 \\
\hline greatest desire to be a leader & 38.267 & 4 & \\
\hline
\end{tabular}

Source: Survey data

Interpretation:The pearson chi-square test statistics basically expresses the total difference between 20 observed frequencies and their expected counterparts, the larger its value, the larger the difference between the data and the null hypothesis.The p-value, denoted by 'Asymp.Sig'. is (.000) for all the variables namely 
Teamwork, Clear communication, Good planning, Good interpreter, Seeking advice, Enjoy analyzing, Problem solver, Delegation of work, Effective complaint handler, Good at directing, Good at developing goals, Appraising performance, Accept mistakes, Resolve conflicts, Believe in diversity, Thrive in change, Greatest desire to be a leader. These variables are significant and are dependent. This means that there's a $0 \%$ chance to find the observed (or a larger) degree of association between the variables if they're perfectly independent in the population. The following three variables i.e Interpersonal relationships, Comfortable in giving advices and Good at implementing techniques are not significant and are dependent on the situations.

\section{Dominant leadership capabilities among the young women:}

People usually learn leadership best by doing, self-awareness of competencies helps to improve and progress in the leadership journey. It is a fundamental belief that management and leadership training should always start with the strong self-leadership. Self leadership/self awareness is an enabling process, where by a person learns to know him/herself better, through this better self understanding he /she is able to steer his/ her life better. The following are the leadership capabilities which are been tested and important four factors are been loaded and proved that these are important factors for having leadership capabilities among the young women.

Table: 2

\begin{tabular}{|l|l|l|}
\hline \multicolumn{2}{|c|}{ Distribution of leadership capabilities of young women } \\
\hline & Initial & Extraction \\
\hline Team work & 1.000 & .735 \\
\hline Clear communication & 1.000 & .836 \\
\hline Interpersonal relationship & 1.000 & .766 \\
\hline Good planning & 1.000 & .778 \\
\hline Good interpreter & 1.000 & .725 \\
\hline Seeking advice & 1.000 & .744 \\
\hline Enjoy analyzing & 1.000 & .793 \\
\hline Problem solver & 1.000 & .802 \\
\hline Comfortable in giving advises & 1.000 & .824 \\
\hline Delegation work & 1.000 & .807 \\
\hline Effective complaint handler & 1.000 & .710 \\
\hline Good at directing & 1.000 & .713 \\
\hline Good at developing goals & 1.000 & .783 \\
\hline Good at implementing techniques & 1.000 & .833 \\
\hline Appraising performance & 1.000 & .712 \\
\hline Accept mistakes & 1.000 & .802 \\
\hline Resolve conflicts & 1.000 & .441 \\
\hline Believe in diversity & 1.000 & .865 \\
\hline Thrive in change & 1.000 & .841 \\
\hline Greatest desire to be a leader & 1.000 & .817 \\
\hline & & \\
\hline
\end{tabular}

Source: Survey data

Interpretation: The factors loaded on the rotated component matrix on the first factor Teamwork are clear communication, good planning, seeking advice, enjoy analyzing, problem solver, good at directing and having greatest desire to be a leader. A young aspiring woman who has all these components is indicative factors for their capability. The factors loaded on the second component clear communication is team work, good at developing goals, accept mistakes, believe in diversity, thrive in change and greatest desire to be a leader. The factors loaded on the third component interpersonal relationship are good interpreter, delegation of work, effective complaint handler and good at implementing techniques. The factors loaded on the fourth factor i.e good planning are interpersonal relationship and very comfortable in giving advices which indicates they are good at delegating the authority and getting the things work out for the good of the organizations.

Table: 3 Distribution of variance of leadership capabilities of young women

\begin{tabular}{|l|l|l|l|l|l|l|l|l|l|l|}
\hline \multirow{2}{*}{ Component } & \multicolumn{3}{|l|}{ Initial Eigen values } & \multicolumn{3}{l}{$\begin{array}{l}\text { Extraction Sums of Squared } \\
\text { Loadings }\end{array}$} & \multicolumn{2}{l}{$\begin{array}{l}\text { Rotation Sums of Squared } \\
\text { Loadings }\end{array}$} \\
\cline { 2 - 11 } & Total & $\begin{array}{l}\% \text { of } \\
\text { Variance }\end{array}$ & $\begin{array}{l}\text { Cumulative } \\
\%\end{array}$ & Total & $\begin{array}{l}\% \text { of } \\
\text { Variance }\end{array}$ & $\begin{array}{l}\text { Cumulative } \\
\%\end{array}$ & Total & $\begin{array}{l}\% \text { of } \\
\text { Variance }\end{array}$ & $\begin{array}{l}\text { Cumulative } \\
\%\end{array}$ \\
\hline Team work & 11.150 & 55.750 & 55.750 & $\begin{array}{l}11.15 \\
0\end{array}$ & 55.750 & 55.750 & 5.252 & 26.261 & 26.261 \\
\hline Clear Communication & 1.837 & 9.185 & 64.935 & 1.837 & 9.185 & 64.935 & 4.704 & 23.522 & 49.782 \\
\hline $\begin{array}{l}\text { Interpersonal } \\
\text { relationship }\end{array}$ & 1.285 & 6.426 & 71.361 & 1.285 & 6.426 & 71.361 & 2.951 & 14.755 & 64.538 \\
\hline Good Planning & 1.053 & 5.266 & 76.628 & 1.053 & 5.266 & 76.628 & 2.418 & 12.090 & 76.628 \\
\hline
\end{tabular}

Source: Survey data 


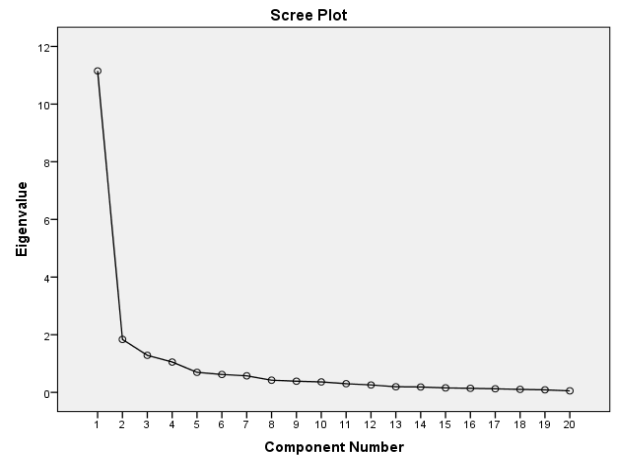

Fig: 1 Graphical representation of leadership capability components.

\section{Motivations play a Key Role:}

\section{Recommendations}

Increasing intrinsic motivation of the employees is the responsibility of top managers in the organization this can be done by congratulating your staff and a job well done appreciation can increase motivation levels and helps in your business growing at an exponential rate. While it is important that your compensation plan helps attract and retain great employees effectively, numerous studies show that recognition is a much better retention tool and performance motivator than money. Extrinsic motivation is a reward: a pay raise, a cash bonus, a gift. Intrinsic motivation comes from inside a person: it's a sense of achievement, responsibility, job satisfaction, purpose, involvement, empowerment and ownership - all the things that make an employee feel that what they're doing makes a big difference in their lives and in the organization itself. If employees feel that what they're doing is insignificant, they'll feel insignificant; if, in turn, they feel their work is valued, they feel valued. The easiest way to provide intrinsic motivation is to say thank you. Recognizing your employees with comments like: "Well done" or "Great job" creates a greater and longer-term effect on employee motivation than providing a cheap reward that's quickly forgotten. Best of all, in most cases intrinsic motivation doesn't cost a cent.

\section{Conclusion}

One cannot exist in harmony without the other and it all starts with the self. This is the foundation of any woman's legacy. The self is the whole package of spirituality, health, personal grooming and education. The sense of well being then reflects on every facet of life-family and work. The secret is to put your own oxygen mask on first to be empowered to support and nurture the people around you. Institutions need to be geared up in preparing the ground for the leaders at the academic learning. As young women from different back ground come for acquiring the knowledge they need to be prepared by creating some corporate simulations in the class rooms. These simulated environments will create a culture in which inquiry is valued and mistakes are viewed as learning opportunities. Strategic young leaders in the class rooms will be the focal point for organizational learning. They promote a culture of inquiry, and they search for the lessons in both successful and unsuccessful outcomes. They study failures their own and their teams 'in an open, constructive way to find the hidden lessons.

\section{Acknowledgements}

I would like to thank all the students who have responded the questionnaire with patience.

\section{References}

[1]. Akinboye, S. (2004) Paradox of Gender Equity in Nigerian Politics, Lagos, Concept Publication Limited.

[2]. Shapiro, M., Ingols, G., O'Neill, R. ve Blake-Beards, S. (2009) "Making Sense of Women as career Self-agents: Implications for Human Resource Development" Human Resource Development Quarterly, 20(4):477-501.

[3]. Cole, CA. (2005) Personnel and Human Resource Management, 5"Edition, London, Book Power.

[4]. Bass, B M, Bass \& Stogdill.(1990).Handbook of Leadership: Theory, research, and Managerial applications. New York, The Free Press.

[5]. Sanghamitra Buddhapriya.(1999). Women in Management, APH Publishing Corporation, New Delhi.

[6]. Stogdill, R.M.(1974).Handbook of Literature: A Survey of Literature,New York, Free Press.

[7]. Sanghamitra Buddhapriya.(1999). Women in Management, APH Publishing Corporation, New Delhi.

[8]. Goleman, D. (1999). Emotional competence. Executive Excellence 16(4), 19 April. 